\title{
Penelitian Campuran Aspal Beton Dengan Menggunakan Filler Ampas Tahu
}

\section{Concrete Asphalt Mixture Research Using Tofu Filler}

\author{
Dony Triyatno', Yosef Cahyo², Ahmad Ridwan ${ }^{3}$, Dwifi Aprillia Karisma ${ }^{4}$ \\ ${ }^{1}$ Jurusan Teknik Sipil, Fakultas Teknik, Universitas Kadiri, Jl. Selomangleng 1 Kediri Indonesia. Email : \\ donytri93@gmail.com \\ ${ }^{2}$ Jurusan Teknik Sipil, Fakultas Teknik, Universitas Kadiri, Jl. Selomangleng 1 Kediri Indonesia. Email : \\ yosef_cahyo@unik-kediri.ac.id \\ ${ }^{3}$ Jurusan Teknik Sipil, Fakultas Teknik, Universitas Kadiri, Jl. Selomangleng 1 Kediri Indonesia. Email : \\ ahmad_ridwan@unik-kediri.ac.id \\ ${ }^{4}$ Jurusan Teknik Sipil, Fakultas Teknik, Universitas Kadiri, Jl. Selomangleng 1 Kediri Indonesia. Email : \\ dwifiaprilliakarisma@gmail.com
}

\begin{abstract}
Abstrak
Pembuatan konstruksi jalan di Indonesia banyak menggunakan aspal beton.Penelitian ini bertujuan mengetahui campuran Ampas Tahu dengan menggunakan metode Marshall,untuk mengetahui kadar aspal optimum yang dihasilkan pada campuran aspal beton dengan filler Ampas Tahu, ditinjau dari stabilitas marshall, flow, VIM, $V M A, V F B$, dan MQ.Hal ini belum banyak dilakukan peneliti lain.Metode campuran aspal beton dalam penelitian ini menggunakan aspal minyak AC 60/70.Penelitian ini terdiri dari 5 sampel, masing-masing menggunakan kadar aspal yang berbeda yaitu: 5\%, 5,5\%, 6\%, 6,5\%, 7\% (satu sampel = 3 varian).Tahapan penelitian meliputi agregat kasar batu koral tertahan saringan no. 8 (2,36mm), agregat halus dengan pasir sungai brantas lolos saringan no.8 $(2,36 \mathrm{~mm})$, dan filler menggunakan ampas tahus dengan lolos saringan no. 200 (0,075mm). Hasil dari penelitian ini pada karakteristik Marshall didapat kadar Aspal Optimum 5\% dan 6\% dengan nilai rerata Stabilitas 712 dan 881, Flow 3,3 mmdan 2,4 mm, VIM 4,65\% dan 4,24\% VMA19,29\%dan 17,87\%, nilai VFB 75,41\%dan 76,15\%, dan MQ $271 \mathrm{~kg} / \mathrm{mm}$ dan 433kg/mm.
\end{abstract}

Kata Kunci: Aspal beton; metode marshall; ampas tahu

\begin{abstract}
Road construction in Indonesia uses concrete asphalt. This research aims to find out the mixture of Tofu Dregs by using the Marshall method, to find out the optimum asphalt content produced in the concrete asphalt mixture with Tofu filler, in terms of marshall stability, flow, VIM, VMA, VFB, and MQ. This has not been done by many other researchers. The method of concrete asphalt mixture in this study uses oil asphalt AC 60/70. This study consists of 5 samples, each using a different asphalt content, namely: 5\%, 5.5\%, 6\%, 6.5\%, 7\% (one sample = 3 variants). The research stage included coarse aggregate of coral with a strained filter no. 8 (2,36mm), fine aggregate with Brantas river sand escapes sieve no.8 $(2.36 \mathrm{~mm})$, and fillers use tahas pulp by passing sieve no. $200(0.075 \mathrm{~mm})$. The results of this study on Marshall characteristics obtained Optimum Asphalt levels of 5\% and $6 \%$ with a mean value of Stability 712 and 881, Flow $3.3 \mathrm{~mm}$ and $2.4 \mathrm{~mm}$, VIM $4.65 \%$ and $4.24 \%$ VMA $19.29 \%$ and $17.87 \%$, VFB values $75.41 \%$ and $76.15 \%$, and $M Q 271 \mathrm{~kg} / \mathrm{mm}$ and $433 \mathrm{~kg} / \mathrm{mm}$.
\end{abstract}

Keywords: Concrete asphalt, marshall method, tofu dregs 


\section{PENDAHULUAN}

Aspal beton adalah material konstruksi jalan yang telah dikenal sejak lama dan banyak dipakai dalam pembuatan jalan. Penggunaannya juga meningkat di Indonesia dari tahun ke tahun. Ini karena aspal beton memiliki kelebihan dibandingkan material lain, selain harganya yang dapat lebih murah daripada bahan lain, kekuatannya untuk mendukung muatan kendaraan berat dan dapat dibuat dengan material yang tersedia secara menyeluruh dan dengan ketahanan yang baik terhadap panas dan hujan. Macam perkerasan ini yaitu campuran dari agregat dan aspal untuk material pengikat pada temperatur tertentu.

Ada empat sifat dasar aspal beton yang harus diperhatikan dalam merencanakan campuran aspal beton, seperti stabilitas, durabilitas, fleksibilitas dan mempunyai tahanan terhadap selip (skid resistance). Apabila keempat sifat tidak dapat diwujudkan secara optimum, maka perencanaan campuran aspal beton, seperti halnya perencanaan campurancampuran lain yaitu ada kompromi-kompromi. Karena campuran yang baik harus mempunyai kecukupan dalam keempat sifat di atas.

Pengerasan jalan umumnya menggunakan media aspal. Untuk pembangunan awal ruas-ruas jalan raya ataupun meningkatkanya yang dibutuhkan berdasarkan dengan penambahan luas jalan raya tentunya akan membutuhkan metode perancangan maupun perencanaan yang efektif untuk mendapatkan hasil yang diinginkan dan terbaik, akan tetapi tetap memenuhi fitur keselamatan para pengguna jalan raya dan bagus untuk ekosistem.

Aspal diidentifikasikan sebagai material hitam atau coklat kehitaman, pada suhu kamar dalam bentuk padat hingga sedikit lentur. Apabila dipanaskan sampai suhu panas tinggi, aspal akan berubah menjadi lembel / cair dan bisa mengikat campuran dari agregat pada saat pembuatan aspal beton.

Agregat terdiri dari pasir, gravel, batu koral, slag atau material lain dari bahan mineral alami maupun buatan. Material pengisi atau fillerpada campuran aspal beton yaitubahan yang harus lolos padapenyaringan No.200 (0,075 mm), jumlahfiller yang berlebihanpada campuran dapat menjadilebih kaku dan gampang retak selain membutuhkan aspal dalam jumlah banyak guna memenuhi workability. Sebaliknya jika terlalu sedikitfillerakan menjadibegitu lentur dan gampang terdeformasi akibat tekanan roda kendaraan sampaimembuat jalan raya yang bergelombang. Jenis filleryang bisa dipadukan contohnya : abu batu, semen portland, debu dolomite, abu terbang, debu tanur tinggi pembuat semen dan ampas tahu (dihaluskan untuk filler).

Di dalam penelitian ini saya mencoba menggunakan ampas tahu yang telah dikeringkan sebagai filler. Ampas tahu adalah sisa atau limbah dari pengolahan tahu. Umumnya, ampas tahu ini digunakan oleh masyarakat sebagai pakan ternak. Akan tetapi disini ampas tahu sebagai pengganti bahan filler portland cement. Dalam penelitian ini kandungan filler telah dibatasi antara 2\% sampai $8 \%$ dari total berat campuran aspal beton. Jenis filler atau bahan pengisi dipilih ampas tahu yang dikeringkan.

\section{METODE PENELITIAN}

Pada tahapan ini,pertama yang dilakukan adalah menyiapkan seluruh bahan, dan pengecekkan alatyang akan dipergunakan.Menyiakan bahanbahan sepertiagregat kasar, aspal, agregat halus, filler ampas tahu.

Tabel 1. Standar Pengujian Aspal

\begin{tabular}{clc}
\hline No & \multicolumn{1}{c}{ Jenis Pengujian } & \multicolumn{1}{c}{ Standar Uji } \\
\hline 1 & Penetrasi $25^{\circ} \mathrm{C}(\mathrm{mm})$ & SNI 06 - 2456-1991 \\
2 & Titik Cair $\left({ }^{\circ} \mathrm{C}\right)$ & SNI 06 $-2434-1991$ \\
3 & Pada Daktilitas $25^{\circ}(\mathrm{cm})$ & SNI 06 - 2432-1991 \\
4 & Berat jenis & SNI 06 - 2441 - 1991 \\
5 & Kehilangan berat & SNI 06 - 2440 - 1991
\end{tabular}

(Sumber: Direktorat Jenderal Bina Marga Departemen pekerjaan Umum Republik Indonesia, Spesifikasi Umum 2010 Divisi 6 hal 38).

Tabel 2. Metode Pengujian Karakteristik Agregat Kasar

\begin{tabular}{lc}
\hline \multicolumn{1}{c}{ Jenis Pengujian } & Standart Uji \\
\hline Penyerapan air & SNI 03 $-1969-1990$ \\
Berat jenis & SNI 03 $-1969-1990$ \\
Indeks kepipihan & RSNI T - 01 - 2005 \\
$\begin{array}{l}\text { Keausan agregat menggunakan } \\
\text { mesin los angeles }\end{array}$ & SNI 2417 - 2008 \\
Analisis saringan & SNI 03 - 1969-1990
\end{tabular}

(Sumber: Direktorat Jenderal Bina Marga Departemen Pekerjaan Umum Republik Indonesia, Spesifikasi Umum 2010 Divisi 6) 
Tabel 3. Metode Pengujian Karakteristik Agregat Halus Dan Filler

\begin{tabular}{lc}
\hline \multicolumn{1}{c}{ Jenis Pengujian } & Metode Uji \\
\hline Penyerapan air & SNI 03 $-1970-1990$ \\
Berat jenis & SNI 03 $-1970-1990$ \\
Sand equivalent & SNI 03 - 4428-1997 \\
Analisa penyaringan & SNI 03 - 1968-1990 \\
\hline
\end{tabular}

(Sumber: Direktorat jenderal Bina Marga Departemen Pekerjaan Umum Republik Indonesia, Spesifikasi Umum 2010 Divisi 6)

Metode perencanaan campuran bertujuan untuk mendapatkan campuran aspal beton dari material yang terdapat di lokasi sehingga dihasilkan campuran yang memenuhi spesifikasi yang di tetapkan. Pengujian empiris merupakan metode yang paling banyak dipakai di indonesia, dengan menggunakan alat Marshall.

Pembuatan dan Pengujian Benda Uji. Benda uji dan kadar aspal awal. Menyiapkan benda uji metode marshall dalam kadar seperti dibawah ini: Pada 2 sampel kadar aspalnya diatas nilai $\mathrm{Pb}$. Pada 2 sampel kadar aspalnya dibawah nilai $\mathrm{Pb}$ Kadar aspal $(\mathrm{Pb})-1,0 \%$. Kadar aspal $(\mathrm{Pb})-0,5 \%$. Kadar aspal $(\mathrm{Pb})$. Kadar aspal $(\mathrm{Pb})+0,5 \%$. Kadar aspal $(\mathrm{Pb})+1,0 \%$

Pengujian alat marshall dengan cara benda uji dimasukan atau direndam water bath sampai 30 menit dengan temperatur $60^{\circ} \mathrm{C}$. Pembersihan kepala marshall dan diberi pelumas. Meletakkan benda uji di alat uji marshall yang telah dipasang flow meter dan arloji pembebanan. Pembebanan dilakukan hingga maksimum. Penjelasan di atas digambarkan dalam diagram alur penelitian di bawah ini

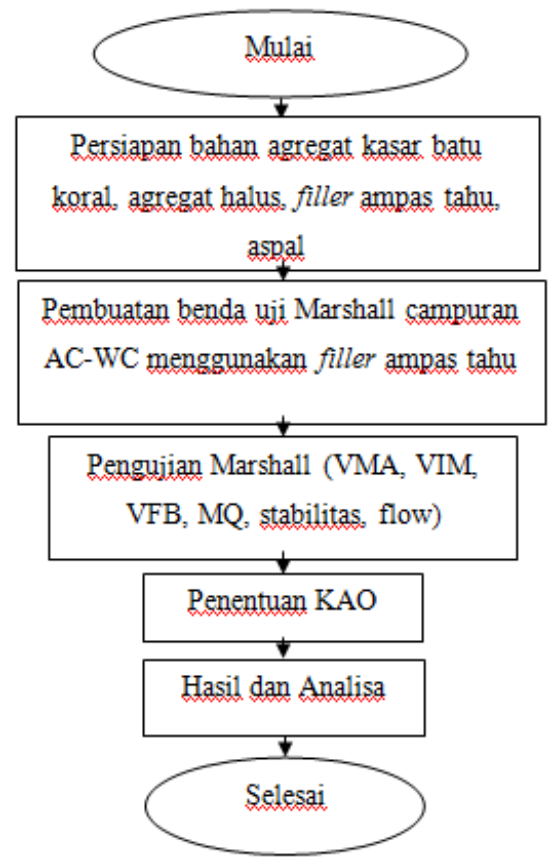

Gambar 1. Alur Penelitian

\section{HASIL DAN PEMBAHASAN}

Di bawah ini menunjukan gambar dari hasil pengujian campuran aspal beton menggunakan filler ampas tahu. Hasil pengujian karakteristik campuran AC-WC dengan Marshall.

Tabel 4. Hasil Uji Rata-rata Karakteristik Marshall

\begin{tabular}{llllllll}
\hline $\begin{array}{l}\text { K. } \\
\text { aspal } \\
\text { Minyak }\end{array}$ & VMA\% & VIM\% & VFB\% & $\begin{array}{l}\text { Sta } \\
\text { bilitas }\end{array}$ & Flow & MQ \\
\hline 1 & $5 \%$ & 19,28 & 4,65 & 75,41 & 712 & 3,3 & 271 \\
2 & $5,50 \%$ & 19,48 & 5,03 & 70,74 & 775 & 3,4 & 248 \\
3 & $6 \%$ & 17,87 & 4,24 & 76,15 & 881 & 2,4 & 433 \\
4 & $6,50 \%$ & 19,54 & 6,61 & 66,11 & 1177 & 3,7 & 283 \\
5 & $7 \%$ & 18,08 & 5,33 & 70,43 & 902 & 3,5 & 216 \\
& & & 3 s/d & Kurang & Kurang & 2 s/d & Mini \\
6 & Spe & $15 \%<$ & $5 \%$ & $65 \%$ & $800 \mathrm{~kg}$ & $\mathrm{~mm}$ & 250 \\
& sifikasi & & & $65 \%$ & dari & 4 & mal \\
\end{tabular}

(Sumber : Data Pengujian Laboratorium Teknik UNIK)

Hubungan antara kadar aspal minyak dengan VIM (Voids In Mix)

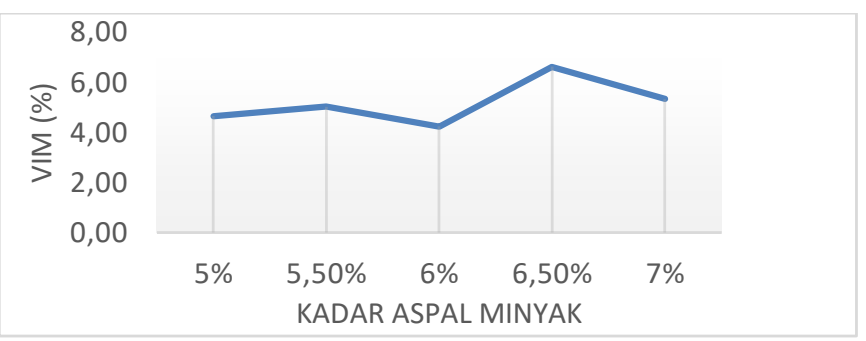

Gambar 2. Hubungan Antara Kadar Aspal Minyak Dengan Nilai Voids In Mix

Berdasarkan gambar 2 menunjukan hasil rata-rata nilai VIMpada kadar aspal 5\%: 4,65\%; 5,5\%: $5,03 \% ; 6 \%: 4,24 \% ; 6,5 \%: 6,61 \% ; 7 \%: 5,33$ $\%$.

Hubungan kadar aspal minyak dengan VMA (Void Mineral Aggregate)

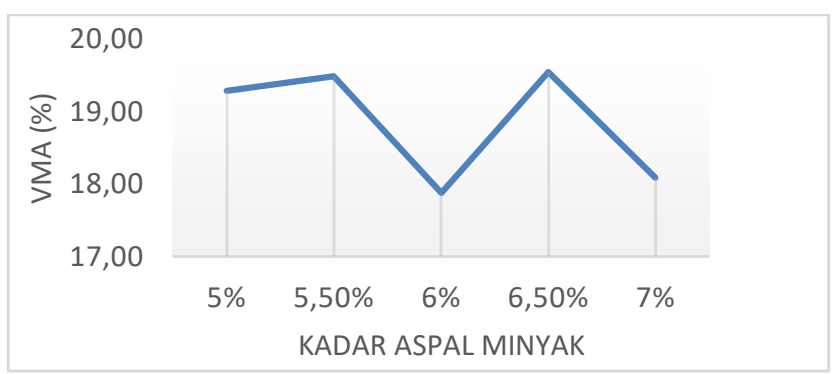

Gambar 3. Hubungan Antara Kadar Aspal Minyak Dengan Nilai VMA 
Berdasarkan gambar 3.menunjukan hasilrata-rata nilai VMApada kadar aspal 5\% : 19,28\% ; 5,5\%: $19,48 \% ; 6 \%: 17,87 \% ; 6,5 \%: 19,54 \% ; 7 \%$ : $18,08 \%$.

Hubungan Kadar Aspal Minyak dengan VFB (Void Filled Bitumen)

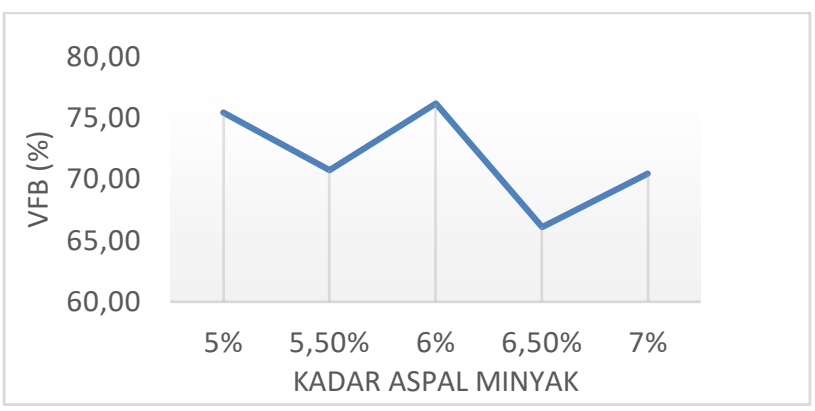

Gambar 4. Hubungan Antara Kadar Aspal Minyak Dengan Nilai VFB

Berdasarkan gambar 4.menunjukan hasilrata-rata nilai VFBpada kadar aspal 5\%:75,41\%;5,5\%: $70,74 \%$; 6\% : 76,15\%; 6,5\%:66,11\%; 7\% : $70,43 \%$.

Hubungan Kadar Aspal Minyak dengan Stabilitas

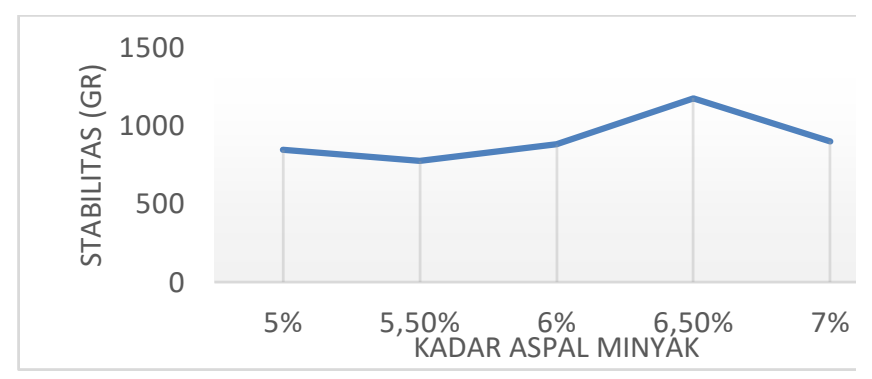

Gambar 5. Hubungan Antara Kadar Aspal Dengan Nilai Stabilitas

Berdasarkan gambar 5.menunjukan hasilrata-rata nilai Stabilitas pada kadar aspal 5\%: $712 \mathrm{~kg} / \mathrm{mm}$; 5,5\%: $775 \mathrm{~kg} / \mathrm{mm} ; 6 \%: 881 \mathrm{~kg} / \mathrm{mm} ; 6,5 \%: 1177$ $\mathrm{kg} / \mathrm{mm} ; 7 \%: 902 \mathrm{~kg} / \mathrm{mm}$.
Hubungan Kadar Aspal Minyak dengan FLOW

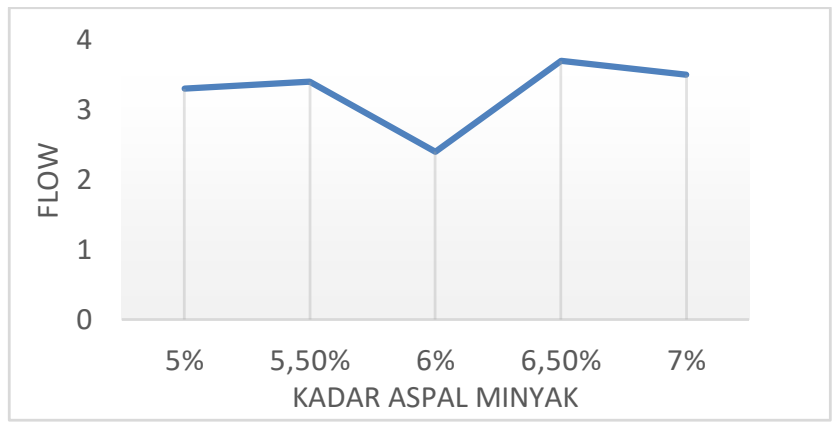

Gambar 6. Hubungan antara kadar aspal dengan nilai Flow

Berdasarkan gambar 6.menunjukan hasilrata-rata nilai Flow ada kadar aspal $5 \%: 3,3 ; 5,5 \%: 3,40$; $6 \%: 2,40 ; 6,5 \%: 3,7 ; 7 \%: 3,5$.

HubunganKadar Aspal Minyak dengan Marshall Quetiont (MQ)

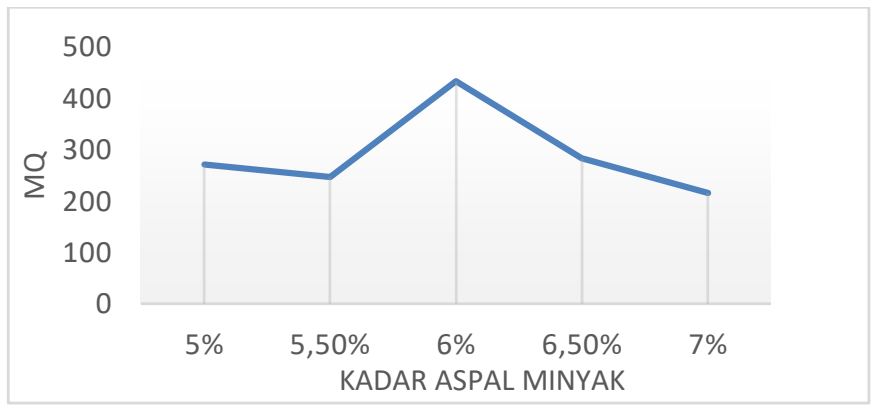

Gambar7. Hubungan Kandungan Kadar Aspal Minyak Dengan Marshall Quetiont

Berdasarkan gambar 7 menunjukan hasil rata-rata nilai MQ pada kadar aspal 5\%: $271 ; 5,5 \%: 248$; $6 \%: 433 ; 6,5 \%: 283 ; 7 \%: 216$.

\section{KESIMPULAN}

Kesimpulan pada uji campuran aspal beton dengan menggunakan filler ampas tahu dengan menggunakan alat uji marshall yang telah dilakukan di Laboratorium Teknik Universitas Kadiri yaitu berdasarkan dari hubungan antara minyak dan kandungan kadar aspal dan volumetric dan semua parameter marshall menggunakan filler Ampas Tahu telah memperoleh kandungan aspal optimum yang berada di kadar aspal5\% dan 6\% dari nilai VIM, VMA, VFB, stabilitas dan MQ. 
.Dari penelitian yang telah dilakukan, jadi saran yang dapat diberikan untuk kedepanya diharapkan agar pada saat pembuatan filler langsung mengeringkanya dengan tungku atau oven pembakar supaya filler yang diperoleh lebih cepat dan lebih banyak.Dan untuk penelitian kedepanya lagi diharapkan agar menggunakan aspal minyak dengan kualitas yang lain dan agregat dengan kualitas yang lain juga untuk mendapatkan hasil yang berbeda dan bisa di terapkan untuk pembuatan jalan raya

\section{REFERENSI}

A. Gunarto, A. I. Candra, F. Teknik, and U. Kadiri, "PENELITIAN CAMPURAN ASPAL BETON DENGAN MENGGUNAKAN FILLER BUNGA PINUS," Ukarst, vol. 3, no. 1, pp. 46-55, 2019.

S. Q. Aini, "Kinerja Beton Aspal Ac-Wc Menggunakan," vol. 01, pp. 78-85.

S. Sunarjono, "Evaluasi Engineering Bahan Perkerasan Jalan Menggunakan Rap Dan Foamed Bitumen," J. Eco Rekayasa, vol. 2, no. 2, pp. 65-71, 2006.

A. L. Toruan, O. H. Kaseke, L. F. Kereh, and T. K. Sendow, "Jenis Maksimum Campuran," J. Sipil Statik, vol. 1, no. 3, pp. 190-195, 2013.

B. Edison, "Karakteristik Campuran Aspal Panas (Asphalt Concrete-Binder Course) Menggunakan Aspal Polimer," J. Aptek, vol. 2, no. 1, pp. 60-71, 2014.

A. Muldiyanto, "Uji Stabilitas Terhadap Flow Campuran Aspal Dengan Marshall Test (Kadar Aspal $5 \%$, Penetrasi 60/70)," J. Pengemb. Rekayasa dan Teknol., vol. 13, no. 1, p. 11, 2011.

G. S. Utami, N. Rohmania, and J. T. Sipil, "PENAMBAHAN ABU SLAG BAJA SEBAGAI BAHAN PENGGANTI FILLER," vol. 4, no. 1, pp. 31-44, 2014.

H. F. \& M. WAHYUDI, "Perencanaan Campuran Aspal Beton Dengan Menggunakan Filler Kapur Padam," 2010.

E. Gardjito, A. I. Candra, and Y. Cahyo, "PENGARUH PENAMBAHAN BATU KARANG SEBAGAI SUBSTITUSI AGREGAT DALAMPEMBUATAN HALUS BLOCK," pp. 36-42.

PAVING

M. Tugas, "STUDI PERENCANAAN TEBAL LAPISAN PERKERASAN TAMBAHAN ( OVERLAY ) PADA PROYEK PENINGKATAN JALAN PROPINSI JURUSAN BINJAI - TIMBANG LAWANG," 2009.
T. L. Ing, D. Setiawan, and R. Simatupang, “Campuran Beton Aspal," pp. 64-67, 2013.

A. Tahir, "Karakteristik campuran beton aspal (ACWC) dengan menggunakan variasi kadar filler abu terbang batu bara," J. SMARTek, vol. 7, no. 4, pp. 256-278, 2009.

A. I. Candra, E. Gardjito, Y. Cahyo, and G. A. Prasetyo, "Pemanfaatan Limbah Puntung Rokok Filter Sebagai Bahan Campuran Beton Ringan Berpori," UKaRsT, vol. 3, no. 1, p. 82, 2019.

R. A. Arisman, "Uin Alauddin Makassar," Uin Alauddin Makasar, pp. 1-86, 2017.

A. Kasar, K. Long, and I. Dan, "Pengaruh penambahan abu sekam padi terhadap kuat tekan beton dengan agregat kasar koral long iram dan agregat halus pasir mahakam," vol. 1, no. November 2017.

B. A. Razak and H. Djufri, "Uji Karakteristik Campuran Ac-Wc Dengan Kandungan Lumpur Pada," vol. 2018, pp. 31-36, 2018.

M. K. Umam, L. Noerochim, and T. Wicaksono, "Pengaruh Komposisi Filler Limbah Cangkang Kerang dan Fiberglass terhadap Sifat Fisis dan Mekanik Komposit untuk Aplikasi Papan Partikel Semen," vol. 8, no. 2, pp. 118-123, 2019.

R. A. Hamzah, O. H. Kaseke, and M. M. Manoppo, "Kriteria Marshall Pada Campuran Beraspal Panas Jenis Lapis Tipis Aspal Beton - Lapis Aus Gradasi," J. Sipil Statik, vol. 4, no. 7, pp. 447-452, 2016.

P. C. Ator et al., "Kriteria Marshall Pada Campuran Lapis Aspal Beton-Lapis Antara Bergradasi Halus," vol. 3, no. 12, pp. 813-820, 2015.

S. Subekti, "Pengolahan limbah cair tahu menjadi biogas sebagai bahan bakar alternatif," Pros. Semin. Nas. Sains dan Teknol. ke-2, no. 1, pp. 61-66, 2011.

C. Bearing, "Optimasi Kadar Aspal pada Stabilisasi Tanah Pasir Menggunakan Aspal dengan," vol. 14, no. 2, pp. 127-132, 2011.

I. Ngurah Wardana. 2009. "Kelakuan Tanah Dengan Sifat Kembang-Susut Yang Tinggi Pada Stabilisasi Tanah Dengan Bahan Serbuk Marmer Dan Bahan Stabilia," J. Ilm. Tek. Sipil, vol. 13, no. 2.

B. M. Das. 1988. "Mekanika Tanah Rekayasa Geoteknis," lnstitut Teknologi 10 Nopember.

S. A. Dwi Sabda Budi Prasetya1, Seto Priyambodo2. 2008. "Pengolahan Emas Tradisional Di Propinsi Ntb," vol. 4, no. 2, pp. 91-93.

T. R. Raswitaningrum and Juliayatna. 2017. "Penambahan Semen Dan Abu Sekam Padi Proteksi/Juni 2020 Volume 2 No. 1 
Untuk (American Association of State Higway," no. November, pp. 1-2.

A. I. Candra. 2017. "Analisis Daya Dukung Pondasi Strauss Pile Pada Pembangunan Gedung Mini Hospital Universitas Kadiri" Ukarst, vol. 1 , no. 1, pp. 63-70.

I. Adha. 2017. "Pengaruh durabilitas terhadap daya dukung stabilisasi tanah menggunakan lempung plastisitas rendah dengan kapur," no. 1.
A. I. Candra, E. Gardjito, Y. Cahyo, and G. A. Prasetyo. 2019. "Pemanfaatan Limbah Puntung Rokok Filter Sebagai Bahan Campuran Beton Ringan Berpori," UKaRsT, vol. 3 , no. 1, p. 82 . 